\title{
Concept of systemology of general transport infrastructure
}

\author{
Ruben Kazaryan ${ }^{1 *}$ \\ ${ }^{1}$ Moscow State University of Civil Engineering, 129337, 26 Yaroslavskoe shosse, Moscow, Russia
}

\begin{abstract}
The fundamental modernization of the transport industry, which began in the mid-nineties of the last century, required the implementation of new approaches to building an integrated transport system of the country through the intensive integration of all types of transport. This caused not only the introduction of new organizational and management processes in transport, but also the consolidation of the activities of transport industry scientists to the development of new industry documents and the revision of existing ones. The problems of economic substantiation of decisions in the field of integrated use of the country's integrated transport system are particularly acute. Therefore, there is an urgent need to create a systemology of the general transport infrastructure on the basis of a modern scientific and methodological assessment of the effectiveness of the integrated use of various types of transport, including: criteria for assessing the effectiveness of transport for ensuring the national security of the country; economic and mathematical models of the integrated use of various types of transport in the interests of ensuring the national security of the country; methods of economic substantiation of the integrated use of transport in the interests of ensuring the national security of the country; scientific and methodological recommendations for improving the economic efficiency of transport for ensuring the national security of the country
\end{abstract}

\section{Introduction}

There are problems in the use of the integrated transport system of the country, including problems of its preparation for work in emergency situations, as well as ensuring the viability of the country's transport system. Preparation of transport for work in a special period involves the solution of a complex of tasks: defense and mobilization preparation of transport; technical protection of transport communications. The viability of the transport network is provided by a set of measures aimed at preserving or restoring its working capacity under the impact of damaging factors of emergencies. Previously developed scientific and methodological foundations and practical recommendations on mobilization preparation and increasing the viability of transport communications as an integrated transport system of the country do not take into account the new realities of a market

\footnotetext{
*Corresponding author: r.kazarian@,mail.ru
} 
economy and require certain adjustments. It is necessary to develop a strategy for modeling the most important long-term purposes and objectives in a specific problem area, and also, taking them into account, develop the course for implementing actions and handling the necessary resources that can ensure the achievement of the intended purposes and objectives. High dynamics of transport support of economic, socio-demographic and environmental security in a market economy require the creation of the concept of a systemology of the integrated use of transport in the interests of the national security of Russia.

\section{Materials and Methods}

In the study, the following general scientific methods were used - systems analysis, logical and mathematical modeling, systems theory and others, as well as methods of operations research and economic and mathematical methods. The level and efficiency of the development of the regulatory and technical base is the key to ensuring the improvement of the quality of design, construction and reconstruction of engineering structures, including roads. The regulatory industry base is replenished mainly due to the revising of existing regulatory documents on the design and construction of transport facilities. At the same time, due to the accepted competitive basis for the selection of executors of research topics with the subsequent development of documents, often the quality of the revised document is unsatisfactory. Newly developed documents have the status of Russian State Standard, guidelines, organizations' standards. However, these documents, especially the organizations' standards, are not developed under a single system. Standards of the organization solve private issues that are also not united by a common theoretical and methodological basis. In addition, the Transport Strategy of the Russian Federation until 2030 plans to increase the density of public roads from $5 \mathrm{~km}$ per 1 thousand people in 2007 to $10 \mathrm{~km}$ per 1 thousand people in 2030 . It is planned to increase the length of public roads from $40 \%$ in 2007 to $80 \%$ in 2030 . To implement such ambitious plans, the main directions of development of the scientific support of the transport industry have been formulated. The main ones are: conducting exploratory and basic research to improve the design of transport facilities, roads; research methods for improving the reliability and durability of road construction; creation of new competitive materials and technologies. These purposes should be unchanged in the long term, and the processes of their achievement will provide the concept of systemology

\section{Results}

It is proposed to assess the efficiency of the transport support of national security by a system of indicators, some of which may become criteria, others - limitations. To substantiate the system of efficiency indicators, a method is proposed that is implemented in several stages. The development of methods and models of economic efficiency of the integrated use of various types of transport in the interests of ensuring the national security of the country will help to resolve the contradiction of the practice of integrated use of the transport system and the state of the scientific and methodological base. The development of a strategy does not lead to immediate actions. Its result is the identification of the general directions of unconditional resolution of the problems that have arisen, focusing on certain tasks and the possibilities for solving them; exclusion of alternative opportunities as incompatible with the chosen strategy. At the stage of strategy development, one has to use 
generalized, incomplete and inaccurate information, which is then concretized when developing different concepts for the implementation of the chosen strategy. In concepts, elements of the strategy act as criteria (benchmarks and tasks). The most important factor in the modeling of key efficiency indicators is the economic and mathematical modeling of multi-criteria assessment of the economic and mathematical foundations of a system target approach to managing the elements of transport production quality systems. Let's consider some of them [1-5]:

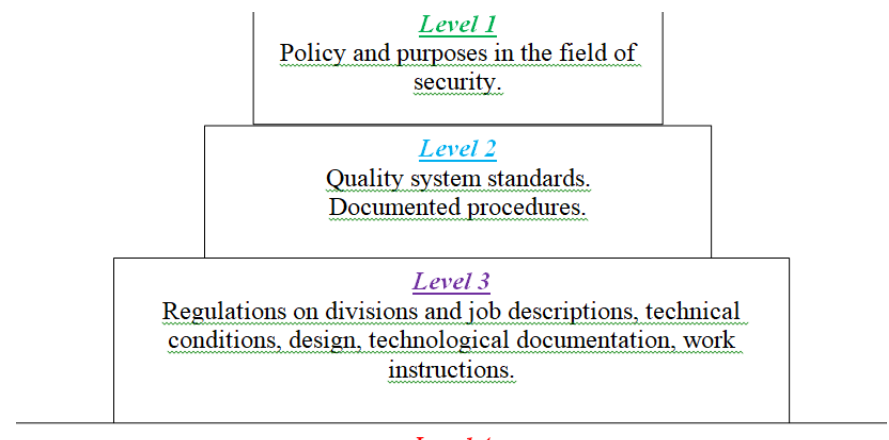

Level 4

Accounting and reporting documents (protocols, acts, logbooks, reports, requirements, planning and statistical documentation, etc.), organizational and administrative documentation (incoming and outgoing correspondence; orders, decrees, notifications; memos, work-related emails, etc.)

Fig.1. Formation of a system of purposes for the transport support of national security. The construction (decomposition) of the purpose system is shown.

The principal difference between the "criterion" and "restrictions" is that the criterion is of an extreme nature and is written in the form:

$$
K \rightarrow \min (\max )
$$

The restriction is written in the form of inequalities:

$$
R \geq R_{\max } \text { or } R \leq R_{\max }
$$

Restrictions allow development of a set of competitive solutions, and the criterion allows choosing the best (one or several) of them. The criterion can be simple (i.e. consists of one indicator) or complex (of several simple indicators).

Identification of efficiency indicators for achieving a global purpose $P_{0}$ in peacetime (in Figure 1 , they are marked with the symbols $\mathrm{K}_{01}, \mathrm{~K}_{02}, \ldots, \mathrm{K}_{0 \mathrm{n}}$ ).

As indicators of the efficiency of use of the transport system of the country (regions), the following are proposed [2-7]:

-the degree of implementation of the planned (projected) traffic volume (volume of transport work).

$$
\begin{aligned}
& \mathrm{K}_{\mathrm{Q}}=\mathrm{Q}_{\mathrm{a}} / \mathrm{Q}_{\mathrm{pl}} \rightarrow \max \\
& \text { or } \mathrm{K}_{\mathrm{Q}}=\mathrm{Q}_{\mathrm{a}} / \mathrm{Q}_{\mathrm{pl}} \rightarrow 1 ;
\end{aligned}
$$

where: $K_{Q}$ - a criterion reflecting the degree of implementation of the directive traffic volume; $\mathrm{Q}_{\mathrm{a}}$ and $\mathrm{Q}_{\mathrm{pl}}$ - actual and planned (directive) traffic volumes, respectively;

-the relative costs of the organization of transport support (the ratio of the actual and maximum allowable costs of transport support):

$$
K_{c}=C_{a} / C_{\max } \rightarrow \min
$$


-socio-demographic efficiency - the degree of implementation of social programs in the region, which is related to the transport support of the population. This criterion is generalized from several simple criteria (the number of settlements that have permanent transport connections with large administrative centers; the time of arrival of an ambulance, etc.). However, all particular criteria can ultimately be reduced to the criterion of social efficiency $S_{e}$ :

$$
S_{e}=N_{b d a c t} / N_{b d \Sigma}
$$

where $N_{\text {bdact }}$ - the actual number of settlements that do not have transport connections with large centers; $N_{b d \Sigma}$ - total number of settlements in the region.

- the degree of safety of goods in the process of transportation, assessed by the coefficient (criterion) of safety $K_{s}$, which is the ratio of the goods actually delivered to consumers by all modes of transport to the planned amount of transported goods $\left(Q_{\Sigma p l a n}\right)$;

-the degree of adaptation of the transport system as a whole and by modes of transport to changes in the living conditions of the country's region (the ability of the transport system to quickly move from normal operation to work in wartime, in emergency situations, and ensure sustainable operation of transport infrastructure in peacetime, wartime, and emergency situations).

-the degree of universality and interchangeability of modes of transport within the overall system of the country's transport system. This criterion characterizes the possibility of transferring goods from one mode of transport to another in case of a damage of one of them. It is measured by the volume of transferred goods and the time of transfer of goods;

- the level of importance of certain types of transport in the overall transport system of the country;

- transportation time $\left(T_{t r}\right)$.

\section{Discussion}

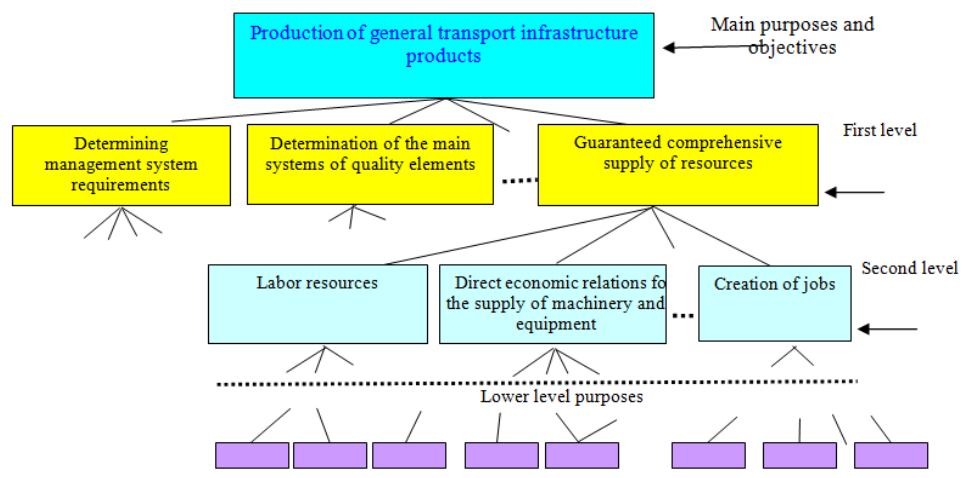

Fig. 2. Example of decomposition of the purposes of transport infrastructure quality management.

Decomposition of the purposes of assessing the efficiency of the transport infrastructure quality management system, taking into account the requirements, is shown in Fig.3. 


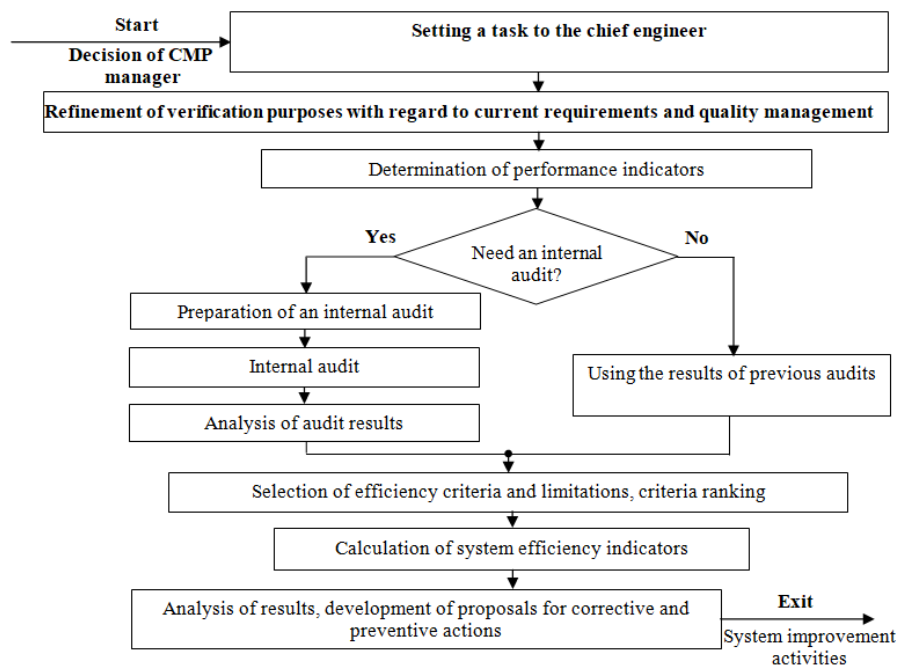

Fig. 3. The project of the efficiency of the transport infrastructure quality management system

The introduction of the methods of economic systems for the study of the system-target approach to the enterprise management led to the creation of an independent direction in mathematical modeling - economic and mathematical modeling. The choice of efficiency criteria, restrictions, and the ranking of particular criteria implies the following [1-3]:

- development and implementation of specialized databases and teaching materials for the design of transport facilities;

- development and implementation of specialized databases and teaching materials for the design of general transport infrastructure facilities;

- development of specialized computer-aided design systems;

- development and implementation of automated systems for end-to-end design;

- improvement of the regulatory base of technology and teaching materials for the design of the general transport infrastructure;

- development and implementation of an integrated system of spatial databases;

- development and implementation of technological solutions and functional applications using digital models (DM).

\section{Conclusions}

The transport complex of Russia and the problems of transport support of its national security are radically different from the Western countries and other developed countries. This is due to the geostrategic and climatic conditions of our country. The integrated transport system is most developed in the European part of the country, where the railways and highways, inland waterways and airways, and pipeline transportation are used quite consistently.

The purpose of transport support of national security is to ensure the state of protection of life and health of people, the environment, goods and vehicles, the sustainability of transport communications and transport infrastructure in normal conditions and in emergency situations.

Intelligence is the most important type of human activity for ensuring the safety of functioning and quality of life. It must necessarily be the initial stage of any other type of 
activity. A person creates a project for any applied activity that he then performs, develops the technology for its implementation, the required resource support and outlines the desired results. In this project, one of the most important elements is the aspect of the "human factor", i.e. anthropotechnical safety of functioning and quality of life.

\section{References}

1. B.A. Lyovin, R.R. Kazaryan, V.O. Chulkov, Infogr. Anthropo. Manag. 1 (2016)

2. B.A. Lyovin, R.R. Kazaryan, V.O. Chulkov, Infogr. Anthropo. Manag. 2 (2016)

3. B.A. Lyovin, R.R. Kazaryan, V.O. Chulkov, Infogr. Anthropo. Manag. 3 (2016)

4. C. Gini, Stats The latest foreign statistical researches (2010)

5. A.A. Lapidus, H.L. Saydaev, Constr Tech Org Influence of parameters of construction company organizational structure development on the generalized index of environmental load. 1 (2012)

6. K.V. Sudakov, V.O. Chulcov, R.R. Kazaryan, O.S. Glazachev, Antropotechnics: Norm in every living thing and artificial beings. Edited by professor Chulcov (2013)

7. A.A. Volkov, V.O. Chulkov, R.R. Kazaryan, S.A. Sinenko, Appl. Mecha. Materia. 584-586, 2681-2684 (2014) doi: 10.4028/www.scientific.net/AMM.584-586.2681. 